\title{
Effect of two GABA-ergic drugs on the cognitive functions of rapid eye movement in sleep-deprived and recovered rats
}

\author{
LIDAO BAO $^{1,2^{*}}$, LENGGE SI $^{1 *}$, YUEHONG WANG $^{1}$, GERILE WUYUN $^{1}$ and AGULA BO ${ }^{1}$ \\ ${ }^{1}$ College of Traditional Mongolian Medicine, Inner Mongolia Medical University, Hohhot, Inner Mongolia 010110; \\ ${ }^{2}$ Department of Pharmacy, Affiliated Hospital of Inner Mongolia Medical University, \\ Hohhot, Inner Mongolia 010059, P.R. China
}

Received January 21, 2015; Accepted March 16, 2016

DOI: $10.3892 / \mathrm{etm} .2016 .3445$

\begin{abstract}
Rapid eye movement (REM) sleep is closely associated with nervous functions. The present study aimed to evaluate the effects of gabazine and tiagabine on the cognitive functions (CF) of REM sleep-deprived and sleep recovered rats. Rats were divided into REM sleep deprivation, blank control (CC) and environmental groups. The REM sleep deprivation group was further divided into non-operation (nonOP), sham-operated (Sham), gabazine (SR) and tiagabine groups. Each group was evaluated over five time points: Sleep deprived for 1 day (SD 1 day), SD 3 day, SD 5 day, sleep recovery $6 \mathrm{~h}$ (RS $6 \mathrm{~h}$ ) and RS $12 \mathrm{~h}$. A rat model of REM sleep deprivation was established by a modified multi-platform water method, with CF assessed by Morris water maze. Hypothalamic $\gamma$-aminobutyric acid (GABA) and glutamic acid contents were measured via high performance liquid chromatography. The number and morphology of hypocretin (Hcrt) neurons and Fos in the hypothalamus, and $\mathrm{GABA}_{\mathrm{A}} \mathrm{R} \alpha 1$-induced integral optical density were detected by immunofluorescence. Compared to the $\mathrm{CC}$ group, the nonOP and Sham group rats $\mathrm{CF}$ were significantly diminished, Fos-positive and Fos-Hcrt double positive cells were significantly increased, and GABA content and $\mathrm{GABA}_{\mathrm{A}} \mathrm{R} \alpha 1$ expression levels were significantly elevated $(\mathrm{P}<0.05)$. The tiagabine and $\mathrm{CC}$ groups exhibited similar results at three time points. The $\mathrm{CF}$ of rats in the SR group were diminished and the number of Fos-positive and Fos-Hcrt double positive cells were significantly increased $(\mathrm{P}<0.05)$ at RS $6 \mathrm{~h}$ and RS $12 \mathrm{~h}$. GABA content and $\mathrm{GABA}_{\mathrm{A}} \mathrm{R} \alpha 1$ expression levels were significantly increased in the SR group at all
\end{abstract}

Correspondence to: Professor Agula Bo, College of Traditional Mongolian Medicine, Inner Mongolia Medical University, 1 Jinshan Street, Jinshan Economic and Technological Development Zone, Hohhot, Inner Mongolia 010110, P.R. China

E-mail: bagulaimmu@163.com

*Contributed equally

Key words: cognitive function, rapid eye movement, rat, $\gamma$-aminobutyric acid time points $(\mathrm{P}<0.05)$, whereas only $\mathrm{GABA}_{\mathrm{A}} \mathrm{R} \alpha 1$ expression levels were significantly increased in the tiagabine group at SD 5 day $(\mathrm{P}<0.05)$. The results of the present study indicated that REM sleep deprivation diminished $\mathrm{CF}$, increased the number of Hcrt neurons, GABA content and $\mathrm{GABA}_{\mathrm{A}} \mathrm{R} \alpha 1$ expression. Furthermore, all alterations were positively correlated with deprivation time and corrected by sleep recovery, as demonstrated by single-factor multi-level variance analysis at the various time points in each group. Therefore, the Hcrt nervous system may be an eligible therapeutic target for the treatment of insomnia.

\section{Introduction}

Rapid eye movement (REM) sleep is important for the development and maturation of animal nervous systems and is associated with thermoregulation and autonomic nervous functions (1). Cerebral oxygen consumption is significantly higher during the REM sleep period, as compared with the strong physical and mental activity states; and cerebral protein synthesis also significantly increases during REM sleep (2). Therefore, REM sleep has an important role in advanced cerebral functions, including learning, memory and emotion, and is the predominant form of recovery for the human body $(3,4)$. However, an increasing number of individuals are suffering from sleep deprivation of varying degrees (5). Previous studies have demonstrated that REM sleep deprivation severely affects cognitive abilities, including learning, memory, logical reasoning, mathematical operations and decision-making, which are damaged to varying extents $(6,7)$. The pathological mechanisms underlying this damage have yet to be fully elucidated.

The sleep-waking cycle is controlled by the two major systems of waking neurons and sleep-promoting neurons. Sleep-promoting neurons are predominantly composed of $\gamma$-aminobutyric acid (GABA) neurons, whereas waking neurons are more diverse (8). Waking neurons comprise various neuronal systems, using numerous neurotransmitters including glutamic acid (Glu), noradrenaline, dopamine, 5-hydroxytryptamine, histamine and acetyl choline (9). The hypocretin (Hcrt) system is correlated with the characterized waking neuron and sleep-promoting neuron systems (10-12). The hypothalamus also has an important role in the regulation of the sleep-waking cycle. Perifornical nucleus (PeF) Hcrt neurons 
receive intensive GABA fiber projection from the preoptic region, indicating that the Hcrt nervous system is associated with the GABA nervous system in the hypothalamus (13-15).

In the present study, normal adult male rats were used to establish models of REM sleep deprivation in order to observe the effect of REM sleep deprivation and revival sleep (RS) of varying degrees on the cognitive functions $(\mathrm{CF})$ of the rats. The following parameters were assessed: Number and morphology of Hcrt neurons; Fos expression levels in the lateral hypothalamic area ( $\mathrm{LH})$ of the hypothalamus; GABA content; and the expression of $\mathrm{GABA}_{\mathrm{A}}$ receptor $\alpha_{1}$ subunit in the hypothalamus. The present study aimed to investigate the effect of REM sleep deprivation on the activity of the hypothalamic Hcrt nervous system and GABA nervous system, as well as the interaction between the two neuron systems and their association with the diminished CF arising from REM sleep deprivation via cerebral stereotaxic surgery and intervention with a PeF micro-dialysis $\mathrm{GABA}_{\mathrm{A}}$ receptor antagonist, gabazine, and GABA re-uptake inhibitor, tiagabine.

\section{Materials and methods}

Experimental animals and groups. A total of 180 male Sprague-Dawley rats, aged 14-16 years and weighing 250-280 g, were purchased from Nanjing Better Biotechnology Co., Ltd. (Nanjing, China). All rats were housed in a controlled temperature $\left(22^{\circ} \mathrm{C}\right)$ and under a 12 -h light/dark cycle with ad libitum access to food and water. The rats were randomly divided into control $(n=60)$ and REM sleep deprivation $(n=120)$ groups. The control group was subdivided into blank control (CC) and environmental control (TC) groups ( $\mathrm{n}=30$ rats/group), and the REM sleep deprivation group was subdivided into the non-operative control (nonOP), sham operation control (Sham), gabazine (SR) and tiagabine groups ( $\mathrm{n}=30 \mathrm{rats} / \mathrm{group})$. Each group was evaluated at five points in time: Sleep deprived for 1 day (SD 1 day), SD 3 day, SD 5 day, sleep recovery 6 h (RS 6 h) and RS 12 h. At total of 6 rats were evaluated at each time point. Following weighing, the rats were maintained in the same cage. The present study was approved by the Ethics Committee of Inner Mongolia Medical University (Hohhot, China).

Reagents and instruments. Gabazine and tiagabine were purchased from Sigma-Aldrich (St. Louis, MO, USA), and gentian violet solution was obtained from Sinopharm Chemical Reagent Co., Ltd. (Shanghai, China). Rabbit anti-Hcrt A polyclonal antibody (cat. no. BA1676) mouse anti-c-Fos monoclonal antibody (cat. no. BM1820), rabbit anti-GABA ${ }_{A} R \alpha 1$ polyclonal antibody (cat. no. BA0873), fluorescein isothiocyanate (FITC)-conjugated goat anti-rabbit immunoglobulin (Ig) G (cat. no. BA1105), cyanine (Cy)3-conjugated goat anti-rabbit IgG (cat. no. BA1032) and horseradish peroxidase (HRP)-conjugated goat anti-mouse IgG (cat. no. BA1051) were purchased from Boster Wuhan Biological Engineering, Co., Ltd. (Wuhan, China). A Universal Morris Water Maze was obtained from Shanghai Jiliang Software Technology Co., Ltd. (Shanghai, China), and the small-scale animal cerebral stereotaxic apparatus was purchased from Stoelting Co. (Wood Dale, IL, USA). The Multiskan MK3 Microplate Reader was purchased from Thermo Fisher Scientific, Inc. (Waltham, MA, USA), the electrophoresis apparatus from Beijing Liuyi Instrument Factory
(Beijing, China), and the Nikon E600 fluorescence microscope from Nikon Corporation (Tokyo, Japan). The QWin Plus image analysis system and VT1200 S tissue slicer were obtained from Leica Microsystems GmbH (Wetzlar, Germany), Photoshop 7.0 software was from Microsoft Corporation (Redmond, WA, USA), and Image-Pro Plus software 7.0 was from Media Cybernetics, Inc. (Rockville, MD, USA). The Varian ProStar 230 high performance liquid chromatography (HPLC) equipment and the 9075 Fluorescence Detector were obtained from Varian Medical Systems, Inc. (Palo Alto, CA, USA), and Star 50c software was from Samsung (Seoul, South Korea). Artificial cerebrospinal fluid (aCSF) was prepared in the laboratory, according to a previous study (16).

Establishment of REM sleep deprivation rat models. Based on the rat localization map outlined by Paxinos and Watson (17), PeF was selected in the rats of the Sham, gabazine and tiagabine groups. A hole (diameter, $1.0 \mathrm{~mm}$ ) was drilled and a stainless steel sleeve was vertically implanted once the cerebrospinal fluid had outflowed. A modified multiple platform REM sleep deprivation method was used to establish a REM sleep deprivation model, as previously described (18). Rats were awoken by nutation or water immersion in order to prevent the rats from entering the REM sleep period, thus leading to REM sleep deprivation. The muscle tone of the rats decreased when they entered the REM sleep period. Rats stayed on the platform for 1 week ( $1 \mathrm{~h}$ daily) prior to the experiment. Subsequently, the Morris water maze test was used to determine alterations in the CF of the rats, as assessed by the escape latencies and space exploratory behavior, following REM sleep deprivation for varying durations and sleep recovery.

Micro-dialysis administration. Micro-dialysis administration was performed on the rats in the Sham, SR, and tiagabine groups during REM sleep deprivation at 8:00-10:00 a.m. each morning (19). Injection was performed slowly at a speed of $1 \mu 1 / 30 \mathrm{sec}$. The rats in the Sham group were injected with $1 \mu \mathrm{laCSF}$, whereas $0.2 \mu \mathrm{M} / \mu 1$ gabazine and $0.5 \mu \mathrm{M} / \mu 1$ tiagabine were dissolved in $1 \mu \mathrm{l}$ aCSF and injected into the rats in the gabazine and tiagabine groups, respectively. The hypothalamic PeF region was observed in CSF extraction to assess the effects of the gabazine $\mathrm{GABA}_{\mathrm{A}}$ receptor antagonist and tiagabine GABA re-uptake inhibitor.

Immunofluorescence staining to assess c-Fos expression in the LH Hcrt neurons of rats. Complete hypothalamus brain tissue was harvested from between the optic chiasma and mammillary body posterior, which was cut vertically and coronally $(20,21)$. Brain tissue was cut into $20 \mu \mathrm{m}$-thick coronal serial sections using a VT1200 S tissue slicer. There were three groups of tissue sections and the sections from each group were stored in separate specimen boxes. The tissue sections were incubated at room temperature for $24 \mathrm{~h}$ with rabbit anti-Hcrt A (1:200) and mouse anti-c-Fos $(1: 4,000)$ monoclonal antibodies. Following washing three times for $5 \mathrm{~min}$ each with PBS, the tissue sections were incubated at room temperature for $4 \mathrm{~h}$ with FITC-conjugated goat anti-rabbit IgG (1:200), Cy3-conjugated goat anti-rabbit IgG (1:200) and HRP-conjugated goat anti-mouse IgG (1:100). For visualization of the HRP-conjugated secondary antibody, the tissue sections were incubated with 3,3-diaminobenzidine (cat. 
Table I. Escape latencies prior to and following REM sleep deprivation ( $\mathrm{n}=6$ rats/group).

\begin{tabular}{|c|c|c|c|c|c|c|}
\hline Time & $\mathrm{CC}$ & $\mathrm{TC}$ & nonOP & ShamOP & Gabazine & Tiagabine \\
\hline SD 1 day & $9.34 \pm 1.31$ & $9.14 \pm 1.91$ & $9.14 \pm 1.83$ & $9.23 \pm 1.06$ & $9.26 \pm 1.52$ & $12.54 \pm 2.42^{\mathrm{a}, \mathrm{b}}$ \\
\hline SD 3 day & $9.78 \pm 1.71$ & $10.07 \pm 2.02$ & $12.16 \pm 2.27^{a, b}$ & $14.23 \pm 1.69^{\mathrm{a}, \mathrm{b}}$ & $11.27 \pm 2.07$ & $14.28 \pm 2.47^{\mathrm{a}, \mathrm{b}}$ \\
\hline SD 5 day & $10.04 \pm 2.07$ & $11.01 \pm 2.01$ & $15.52 \pm 3.32^{\mathrm{a}, \mathrm{b}}$ & $16.20 \pm 2.53^{\mathrm{a}, \mathrm{b}}$ & $12.17 \pm 2.01$ & $17.47 \pm 3.25^{\mathrm{a}, \mathrm{b}}$ \\
\hline RS $6 \mathrm{~h}$ & $9.28 \pm 1.21$ & $10.12 \pm 1.74$ & $13.03 \pm 1.52^{\mathrm{a}, \mathrm{b}}$ & $14.22 \pm 2.47^{\mathrm{a}, \mathrm{b}}$ & $13.46 \pm 2.65^{\mathrm{a}, \mathrm{b}}$ & $11.26 \pm 2.13$ \\
\hline $\mathrm{RS} 12 \mathrm{~h}$ & $9.26 \pm 1.77$ & $10.14 \pm 2.23$ & $10.27 \pm 1.41$ & $11.26 \pm 1.78$ & $14.24 \pm 2.65^{\mathrm{a}, \mathrm{b}}$ & $10.42 \pm 2.27$ \\
\hline
\end{tabular}

${ }^{\mathrm{a}} \mathrm{P}<0.05$ vs. the $\mathrm{CC}$ and $\mathrm{TC}$ groups; ${ }^{\mathrm{b}} \mathrm{P}<0.05$ vs. various time points in the same group and at the same time point in different groups. Data are expressed as the mean \pm standard error of the mean. REM, rapid eye movement; CC, blank control; TC, environmental control; nonOP, non-operative control; ShamOP, sham operation control; SD, sleep deprived; RS, sleep recovery.

Table II. Space exploration behavior prior to and following REM sleep deprivation (n=6 rats/group).

\begin{tabular}{|c|c|c|c|c|c|c|}
\hline Time & $\mathrm{CC}$ & $\mathrm{TC}$ & nonOP & ShamOP & Gabazine & Tiagabine \\
\hline SD 1 day & $8.59 \pm 1.62$ & $8.72 \pm 1.63$ & $8.45 \pm 1.56$ & $8.54 \pm 1.32$ & $8.72 \pm 1.56$ & $5.59 \pm 2.01^{\mathrm{a}, \mathrm{b}}$ \\
\hline SD 3 day & $9.32 \pm 1.40$ & $9.24 \pm 1.75$ & $6.67 \pm 1.21^{\mathrm{a}, \mathrm{b}}$ & $5.77 \pm 2.33^{\mathrm{a}, \mathrm{b}}$ & $8.01 \pm 1.47$ & $5.39 \pm 2.29^{\mathrm{a}, \mathrm{b}}$ \\
\hline SD 5 day & $7.74 \pm 1.55$ & $8.41 \pm 1.67$ & $5.36 \pm 1.56^{\mathrm{a}, \mathrm{b}}$ & $5.42 \pm 1.32^{\mathrm{a}, \mathrm{b}}$ & $8.26 \pm 2.36$ & $4.13 \pm 1.14^{\mathrm{a}, \mathrm{b}}$ \\
\hline RS $6 \mathrm{~h}$ & $9.25 \pm 1.63$ & $8.75 \pm 1.75$ & $6.36 \pm 1.32^{\mathrm{a}, \mathrm{b}}$ & $6.26 \pm 2.06^{\mathrm{a}, \mathrm{b}}$ & $4.65 \pm 1.59^{\mathrm{a}, \mathrm{b}}$ & $7.26 \pm 2.21$ \\
\hline RS $12 \mathrm{~h}$ & $9.28 \pm 1.63$ & $8.71 \pm 2.23$ & $7.45 \pm 1.56$ & $7.59 \pm 2.47$ & $5.47 \pm 1.98^{\mathrm{a}, \mathrm{b}}$ & $7.37 \pm 2.12$ \\
\hline
\end{tabular}

${ }^{\mathrm{a}} \mathrm{P}<0.05$ vs. the $\mathrm{CC}$ and $\mathrm{TC}$ groups; ${ }^{\mathrm{b}} \mathrm{P}<0.05$ vs. various time points in the same group and at the same time point in different groups. Data are expressed as the mean \pm standard error of the mean. REM, rapid eye movement; CC, blank control; TC, environmental control; nonOP, nonoperative control; ShamOP, sham operation control; SD, sleep deprived; RS, sleep recovery.

no. P0203; DAB Horseradish Peroxidase Color Development kit; Beyotime Institute of Biotechnology, Haimen, China). In the blank control group, normal rabbit and goat serum were used as substitutes. Control tissue sections were taken and the steps were completed as before. Staining was evaluated by observation with a Nikon E600 fluorescence microscope. Images were captured and analyzed using the QWin Plus image analysis system.

Determination of GABA and Glu content in the hypothalamus of the rats. The hypothalamus was harvested and cut into sections $(22,23)$. A total of $10 \mathrm{mg}$ hypothalamus tissue was weighed and centrifuged at $5,000 \times \mathrm{g}$ at $0^{\circ} \mathrm{C}$ for $15 \mathrm{~min}$. The supernatant was dissolved in the aCSF at a concentration of $1.0 \mathrm{mmol} / \mathrm{l}$ and refrigerated. The solution was diluted to $10 \mathrm{X}$ and 100X with aCSF prior to use. Varian Prostar 230 HPLC, Star 9075 fluorescence detector and Star software were used for gradient control and chromatographic data treatment and determination of the content of GABA and Glu in the hypothalamus. A calibration curve was plotted with standard concentration vs. peak area. Specimen concentrations were calculated using the external standard method.

Immunofluorescence detection of $G A B A_{A} R \alpha 1$-subunit expression in the hypothalamus of rats. The third group of tissue sections were incubated at room temperature for $24 \mathrm{~h}$ with rabbit anti-GABA $\mathrm{R} \alpha$ l antibody $(1: 200)$, as previously described (24). The tissue sections were subsequently incubated at room temperature for $4 \mathrm{~h}$ with $\mathrm{Cy} 3$-conjugated goat anti-rabbit IgG antibody (1:200). Normal rabbit and goat serum served as the negative control and the subsequent steps were completed as before. The tissue sections were observed under a low-power microscope (Olympus CX23; Olympus Corporation, Tokyo, Japan) to determine the positive expression region. Five fields were selected under a high-power microscope (XTJ-4400; Wuzhou New Found Instrument, Co., Ltd., Wuzhou, China) and an Image Pro Plus 7.0 software was used to analyze the images. The integrated optical density (IOD) was measured on the yellow portion of the image.

Statistical treatment. SPSS 17.5 statistical software (SPSS, Inc., Chicago, IL, USA) was used to perform the statistical analyses. Data were expressed as the mean \pm standard error of the mean. Self-control data prior to and following REM sleep deprivation at each time point in each group were subjected to a t-test of randomized matched pair design data mean. The Levene's test was used to assess homogeneity of variance. Single factor multilevel variance analysis was used to analyze comparisons at various time points in each group. Inter-group comparisons at various time points were assessed via multi-factor variance analysis. $\mathrm{P}<0.05$ was considered to indicate a statistically significant difference.

\section{Results}

Cognitive behavior. Based on the comparison between the nonOP group and Sham group, and the CC group and TC group, the CF at three points in time, SD 3 day, SD 5 day 


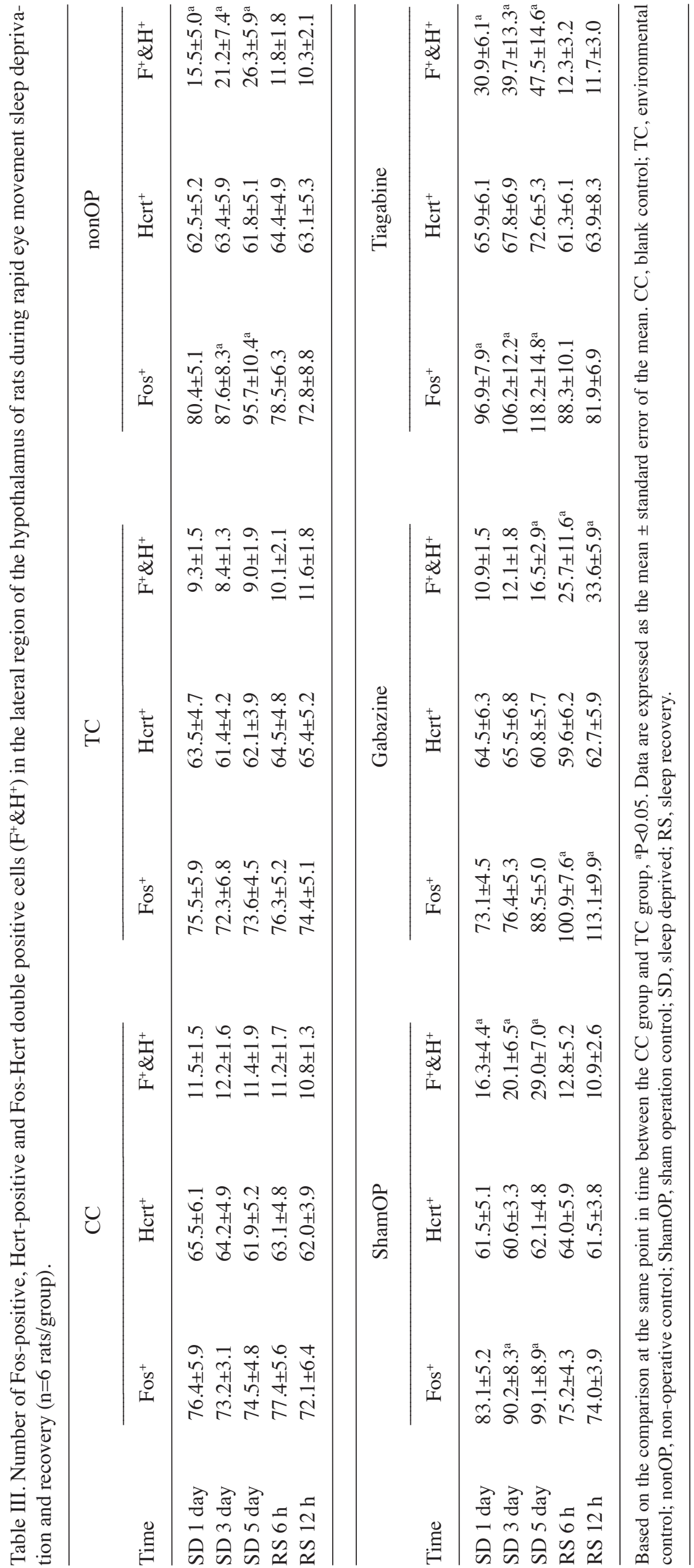


A

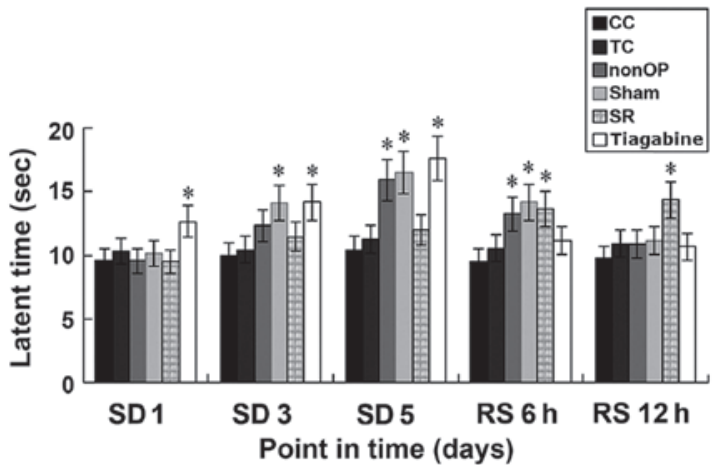

B

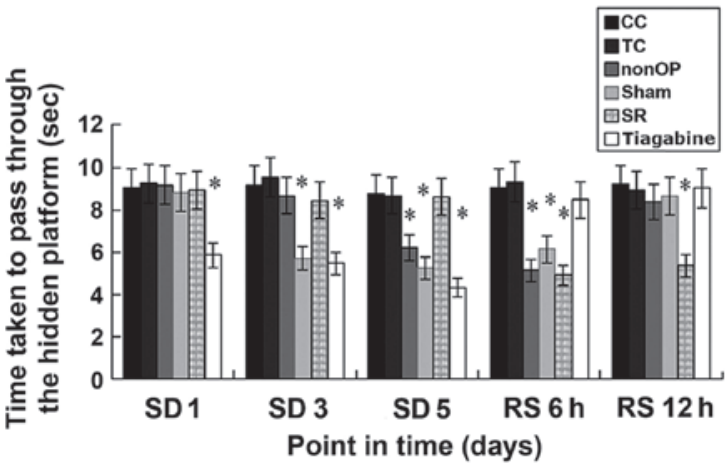

Figure 1. Cognitive function assessment. (A) Escape latency periods prior to and following REM sleep deprivation among and within groups. "P<0.05 vs. the $\mathrm{CC}$ and TC groups and vs. various time points in the same group and at the same time point in different groups. (B) Space explorative behavior prior to and following REM sleep deprivation among and within groups, as demonstrated by the time taken to pass through the hidden platform on a Morris water maze. $\mathrm{P}<0.05$ vs the $\mathrm{CC}$ and $\mathrm{TC}$ groups and vs. various time points in the same group and the same time point in different groups. REM, rapid eye movement; SD, sleep deprived; RS, sleep recovery; CC, blank control; TC, environmental control; nonOP, non-operative control; Sham, sham operation control; SR, gabazine.

and RS 6 h diminished significantly $(\mathrm{P}<0.05)$; however no significant difference in $\mathrm{CF}$ was detected at $\mathrm{SD} 1$ day and RS $12 \mathrm{~h}$. The CF of the rats in the SR group were significantly diminished at SD 1 day, SD 3 day, and SD 5 day $(\mathrm{P}<0.05)$, whereas no significant difference in $\mathrm{CF}$ was detected at RS $6 \mathrm{~h}$ and RS $12 \mathrm{~h}$, as compared with the $\mathrm{CC}$ and TC groups. Furthermore, no significant difference in $\mathrm{CF}$ was detected in the rats in the tiagabine group at SD 1 day, SD 3 day and SD 5 day, as compared with the CC and TC groups; although $\mathrm{CF}$ were significantly diminished at SD 1 day and RS $12 \mathrm{~h}$ $(\mathrm{P}<0.05$; Tables I and II; Fig. 1).

Immunofluorescence staining for c-Fos expression in $\mathrm{LH}$ Hcrt neurons of rats. No significant differences in the number of Fos-positive, Hcrt-positive and Fos-Hcrt double-positive $\left(\mathrm{F}^{+} \& \mathrm{H}^{+}\right)$cells were detected in the lateral region of the hypothalamus of rats in the TC and $\mathrm{CC}$ groups at various time points. The number of $\mathrm{F}^{+} \& \mathrm{H}^{+}$cells was significantly increased in the nonOP, Sham and tiagabine groups at SD 1 day, as compared with the $\mathrm{CC}$ and $\mathrm{TC}$ groups $(\mathrm{P}<0.05)$. The number of the Fos positive cells in the tiagabine group was also significantly increased, as compared with the CC and TC groups $(\mathrm{P}<0.05)$. However, no significant differences in the number of Fos positive cells was detected in various groups, as compared with the CC group and TC group. The number of the Fos-positive and $\mathrm{F}^{+} \& \mathrm{H}^{+}$cells in the nonOP,

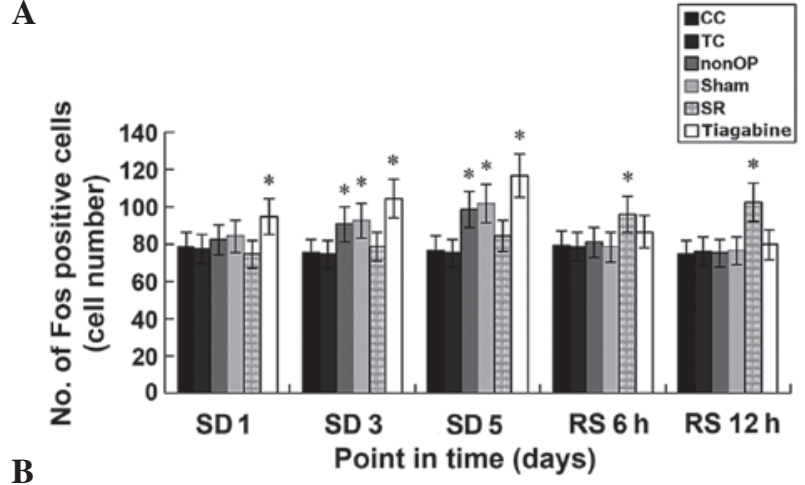

B

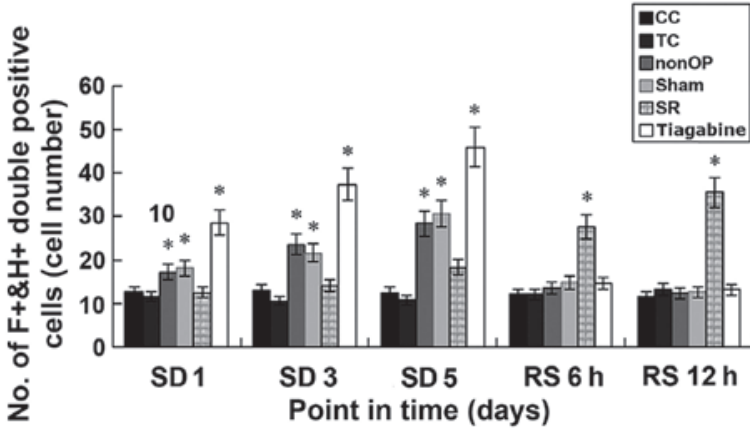

Figure 2. (A) Number of Fos-positive cells among and within groups in the lateral region of the hypothalamus of rats. (B) $\mathrm{F}^{+} \& \mathrm{H}^{+}$cells among and within groups in the lateral region of the hypothalamus of rats among and within groups. " $\mathrm{P}<0.05$, vs. the CC and TC groups. REM, rapid eye movement; $\mathrm{CC}$, blank control; TC, environmental control; nonOP, non-operative control; Sham, sham operation control; SD, sleep deprived; RS, sleep recovery; $\mathrm{SR}$, gabazine; $\mathrm{F}^{+} \& \mathrm{H}^{+}$, Fos-hypocretin double positive.

Sham and tiagabine groups at SD 3 day and SD 5 day was significantly increased, as compared with the CC and TC groups $(\mathrm{P}<0.05)$. However, no significant differences in the number of Fos-positive and $\mathrm{F}^{+} \& \mathrm{H}^{+}$cells were detected in the gabazine group, as compared with the $\mathrm{CC}$ and TC groups. No significant difference in the number of Fos positive cells and $\mathrm{F}^{+} \& \mathrm{H}^{+}$cells were detected at RS $6 \mathrm{~h}$ and $\mathrm{RS} 12 \mathrm{~h}$ in the nonOP, Sham and tiagabine groups, as compared with the $\mathrm{CC}$ and TC groups. However, the number of the Fos-positive cells and $\mathrm{F}^{+} \& \mathrm{H}^{+}$cells in the gabazine group was significantly increased, as compared with the $\mathrm{CC}$ and $\mathrm{TC}$ groups $(\mathrm{P}<0.05$; Table III, Figs. 2 and 3).

GABA and Glu content in the hypothalamus of rats. No significant differences in GABA and Glu content was detected in the hypothalamus of rats in the TC and $\mathrm{CC}$ groups at various time points. Furthermore, no significant differences in Glu content were detected between the various time points in all groups. GABA content was significantly increased in the nonOP, Sham and gabazine groups at SD 1 day, SD 3 day, SD 5 day and RS $6 \mathrm{~h}$, as compared with the $\mathrm{CC}$ and TC groups $(\mathrm{P}<0.05)$. GABA content in the gabazine group at RS $12 \mathrm{~h}$ was significantly increased, as compared with the CC and TC groups $(\mathrm{P}<0.05)$. No significant differences in GABA were detected in the remaining five groups, as compared with the $\mathrm{CC}$ and TC groups. Minor alterations in GABA content were detected in the tiagabine group prior to REM sleep deprivation and following sleep recovery. No significant differences in GABA content was detected at the five time points in the 

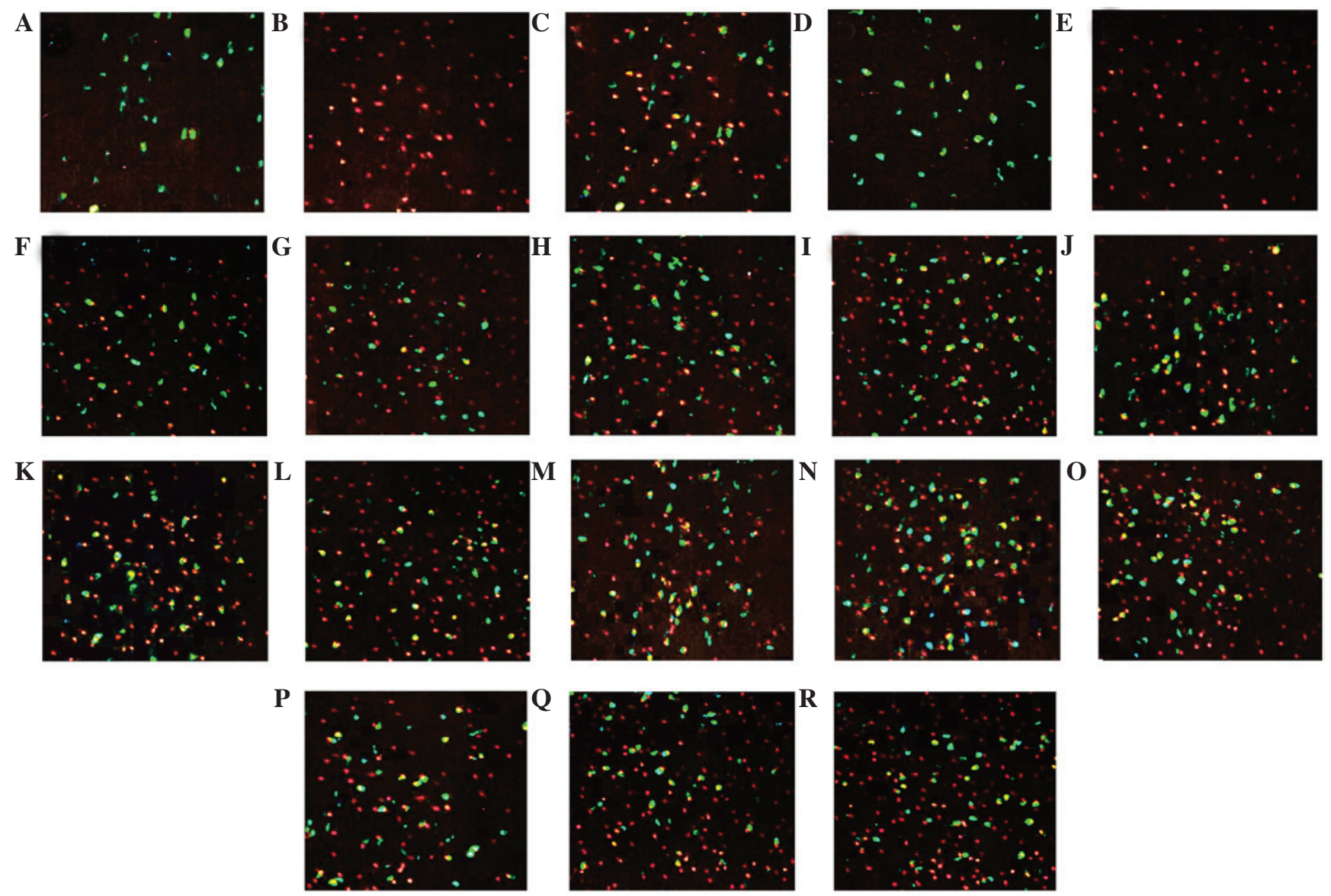

Figure 3. Immunofluorescent staining for lateral Hcrt neurons and Fos in the hypothalamus of rats. Green fluorescence represents fluorescein-stained Hcrt neurons, whereas red fluorescence represents cyanine3-stained Fos (magnification, x20). (A) Hcrt neurons, (B) Fos and (C) Hcrt neurons and Fos double staining at SD 5 day in the CC group; (D) Hcrt neurons, (E) Fos and (F) Hcrt neurons and Fos double staining at SD 5 day in the TC group. Hcrt neurons and Fos double staining at (G) SD 1 day, (H) SD 3 day and (I) SD 5 day in the nonOP group. Hert neurons and Fos double staining at (J) SD 1 day, (K) SD 2 day and (L) SD 5 day in the Sham group. Hcrt neurons and Fos double staining at (M) SD 5 day, (N) RS $6 \mathrm{~h}$ and (O) RS $12 \mathrm{~h}$ in the gabazine group. (P) Hcrt neurons and Fos double staining at SD 1 day, (Q) SD 3 day and (R) SD 5 day in the tiagabine group. Hcrt, hypocretin; SD, sleep deprived; RS, sleep recovery; CC, blank control; TC, environmental control; nonOP, non-operative control; Sham, sham operation control.

tiagabine group, as compared with the same time point in the CC and TC groups (Table IV; Fig. 4A).

Immunofluorescence detection of $G A B A_{A} R \alpha 1$-subunit expression in the hypothalamus of rats. Fluorescence microscopy demonstrated that the Cy3-stained $\mathrm{GABA}_{\mathrm{A}} \mathrm{R} \alpha 1$ $\sigma$-subunits were densely distributed in the whole hypothalamus region and cavities of various sizes were formed at few sites. The immunofluorescence of the tissue sections at SD 1 day, SD 3 day, SD 5 day and RS $6 \mathrm{~h}$ in the nonOP, Sham and gabazine groups was significantly increased, as compared with the remaining time points in the remaining groups. Immunofluorescence peaked at SD 5 day in the gabazine group. For the assessment of the $\mathrm{GABA}_{\mathrm{A}} \mathrm{R} \alpha 1 \sigma$-subunit immunofluorescence IOD, only the result at SD 5 day in the tiagabine group was higher compared with the $\mathrm{CC}$ and $\mathrm{TC}$ groups $(\mathrm{P}>0.05)$. No significant differences in the IOD values of the $\mathrm{GABA}_{\mathrm{A}} \mathrm{R} \alpha 1$ positive regions within the hypothalamus were detected between the TC and $\mathrm{CC}$ groups at various time points. IOD values of the $\mathrm{GABA}_{\mathrm{A}} \mathrm{R} \alpha 1$-positive regions were significantly increased in nonOP, Sham and gabazine groups at SD 1 day, SD 3 day, SD 5 day and RS 6 h, as compared with the $\mathrm{CC}$ and $\mathrm{TC}$ groups $(\mathrm{P}<0.05)$. At SD 5 day, the IOD value of the $\mathrm{GABA}_{\mathrm{A}} \mathrm{R} \alpha 1$ positive regions in the tiagabine group was significantly higher, as compared with the $\mathrm{CC}$ and $\mathrm{TC}$ groups $(\mathrm{P}<0.05)$. The IOD value of the $\mathrm{GABA}_{\mathrm{A}} \mathrm{R} \alpha 1$ positive regions at RS $12 \mathrm{~h}$ in the gabazine group was still significantly increased, as compared with the $\mathrm{CC}$ and TC groups at only SD 5 day $(\mathrm{P}<0.05)$. No statistical differences in IOD values were detected between the remaining five groups and the $\mathrm{CC}$ and TC groups at the RS $12 \mathrm{~h}$ (Table V; Figs. 4B and 5).

\section{Discussion}

To date, various behavioristic methods have been used to investigate learning and memory. The Morris water maze is a universally-accepted objective method for evaluating behavior (25). Rodents are more similar to humans than other animals in sleep physiology (26); therefore rodents are the most suitable for medical research and male rats were selected as the subjects in the present study. Previous studies have determined that rats may succumb to REM sleep deprivation after 6-7 days $(27,28)$. Therefore, in order to avoid data loss due to mortality, the maximum duration of REM sleep deprivation was 5 days in the present study. As it is difficult to distinguish the alterations in CF and other indices, including c-Fos 


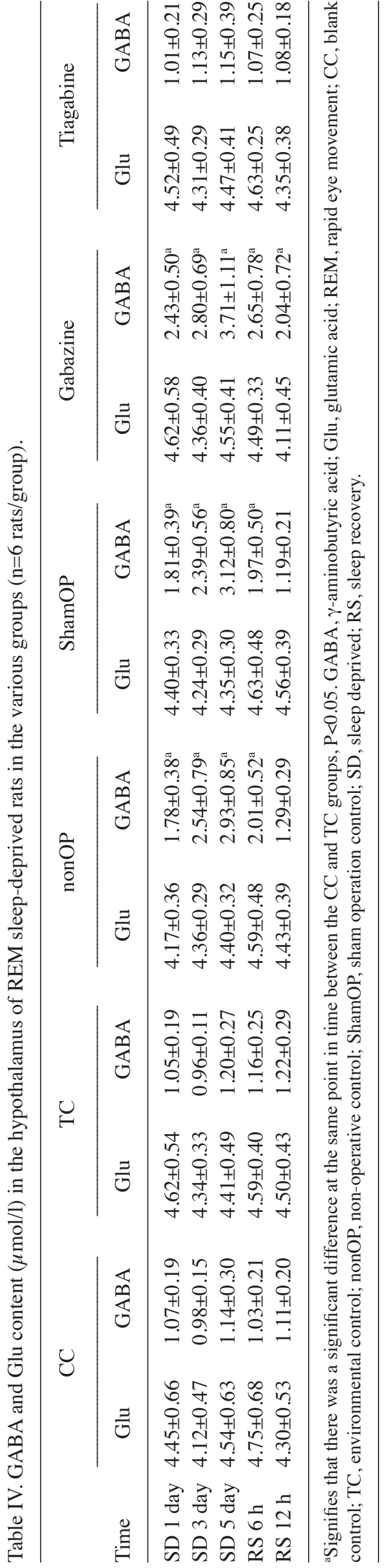

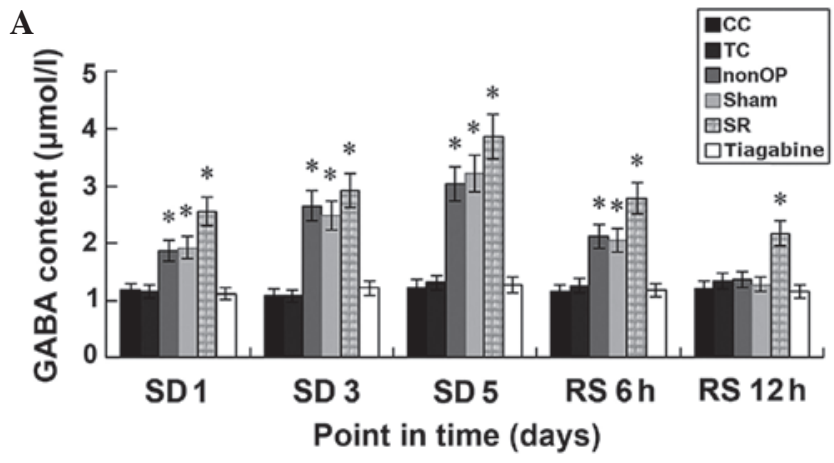

B

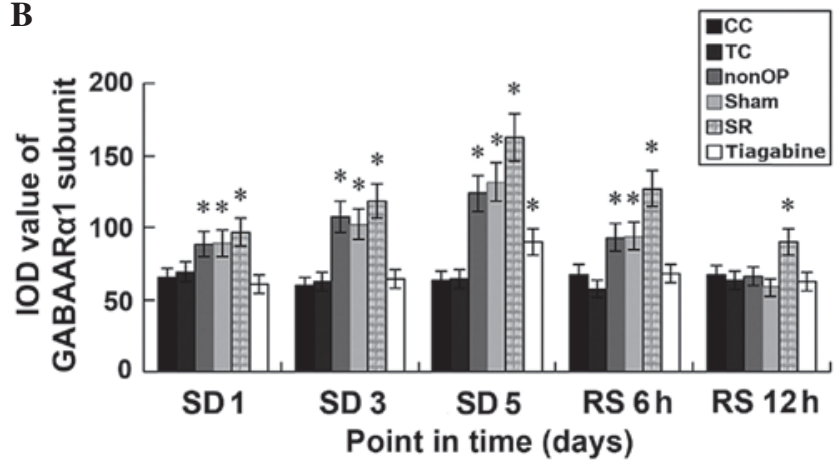

Figure 4. (A) GABA content in the hypothalamus of REM sleep-deprived rats among and within groups. (B) IOD of the $\mathrm{GABA}_{\mathrm{A}} \mathrm{R} \alpha 1 \sigma$ subunits of the hypothalamus of the REM sleep-deprived rats. " $\mathrm{P}<0.05$, vs. the $\mathrm{CC}$ and TC groups at the same time point. GABA, $\gamma$-aminobutyric acid; REM, rapid eye movement; IOD, integrated optical density; CC, blank control; TC, environmental control; nonOP, non-operative control; Sham, sham operation control; SD, sleep deprived; RS, sleep recovery; SR, SR-95531.

expression, GABA and Glu content, induced by REM sleep deprivation over a short period of time $(29,30)$, five points in time (SD 1 day, SD 3 day, SD 5 day, RS 6 h, and RS 12 h) were selected for observation.

Comparing the alterations in $\mathrm{CF}$ among and within groups demonstrated that the overall variation $\mathrm{CF}$ trend in the tiagabine group was consistent with the nonOP and Sham groups, although the degrees of alteration were different. At SD 1 day in the tiagabine group, rats exhibited significantly diminished $\mathrm{CF}$, as compared with the $\mathrm{CC}$ and $\mathrm{TC}$ groups; whereas no differences were detected between the nonOP and Sham groups and the latter two groups. Rats in the tiagabine group exhibited diminished CF at SD 1 day, SD 3 day and SD 5 day, as compared with the nonOP and Sham groups. Furthermore, the CF of rats at RS $6 \mathrm{~h}$ in the tiagabine group exhibited improved recovery, as compared with the nonOP and Sham groups; however, there was no significant difference at RS $12 \mathrm{~h}$ among these three groups. These results indicated that the GABA re-uptake inhibitor exacerbated the decline of $\mathrm{CF}$ in the rats during REM sleep deprivation, whereas it accelerates the improvement of CF following sleep recovery. This is consistent with previous studies which have demonstrated that GABA pharmacological agents can be used to effectively intervene with the alterations in CF during REM sleep deprivation and recovery in rats $(31,32)$.

The number of $\mathrm{F}^{+} \& \mathrm{H}^{+}$cells in the lateral region of the hypothalamus of the rats in the nonOP group following REM sleep deprivation at SD 1 day, SD 3 day and SD 5 day was significantly increased, as compared with the CC and TC 
Table V. Immunofluorescence integrated optical densities of $\mathrm{GABA}_{\mathrm{A}} \mathrm{R} \alpha 1$ sigma subunits in the hypothalamus of rapid eye movement sleep-deprived rats among and within groups.

\begin{tabular}{lcccrrr}
\hline Time & CC & TC & nonOP & Sham & Gabazine & Tiagabine \\
\hline SD 1 day & $63.69 \pm 18.16$ & $66.22 \pm 19.30$ & $86.31 \pm 21.57^{\mathrm{a}}$ & $90.32 \pm 19.87^{\mathrm{a}}$ & $98.65 \pm 29.54^{\mathrm{a}}$ & $58.66 \pm 20.89$ \\
SD 3 day & $56.59 \pm 16.38$ & $60.58 \pm 20.22$ & $105.49 \pm 43.29^{\mathrm{a}}$ & $100.26 \pm 32.16^{\mathrm{a}}$ & $120.55 \pm 39.98^{\mathrm{a}}$ & $62.54 \pm 25.24$ \\
SD 5 day & $61.83 \pm 18.23$ & $62.61 \pm 14.29$ & $119.68 \pm 33.58^{\mathrm{a}}$ & $129.51 \pm 42.35^{\mathrm{a}}$ & $170.46 \pm 51.39^{\mathrm{a}}$ & $88.38 \pm 26.33^{\mathrm{a}}$ \\
RS 6 h & $65.63 \pm 19.21$ & $55.29 \pm 18.38$ & $90.19 \pm 39.82^{\mathrm{a}}$ & $92.11 \pm 33.48^{\mathrm{a}}$ & $131.44 \pm 44.24^{\mathrm{a}}$ & $66.21 \pm 24.61$ \\
RS 12 h & $64.16 \pm 17.12$ & $61.52 \pm 19.11$ & $64.21 \pm 20.19$ & $56.85 \pm 20.17$ & $92.58 \pm 34.98^{\mathrm{a}}$ & $60.28 \pm 19.29$ \\
\hline
\end{tabular}

${ }^{\mathrm{a}} \mathrm{P}<0.05$ at the same point in time between the $\mathrm{CC}$ and TC groups. GABA, $\gamma$-aminobutyric acid; Glu, glutamic acid; $\mathrm{CC}$, blank control; TC, environmental control; nonOP, non-operative control; ShamOP, sham operation control; SD, sleep deprived; RS, sleep recovery.
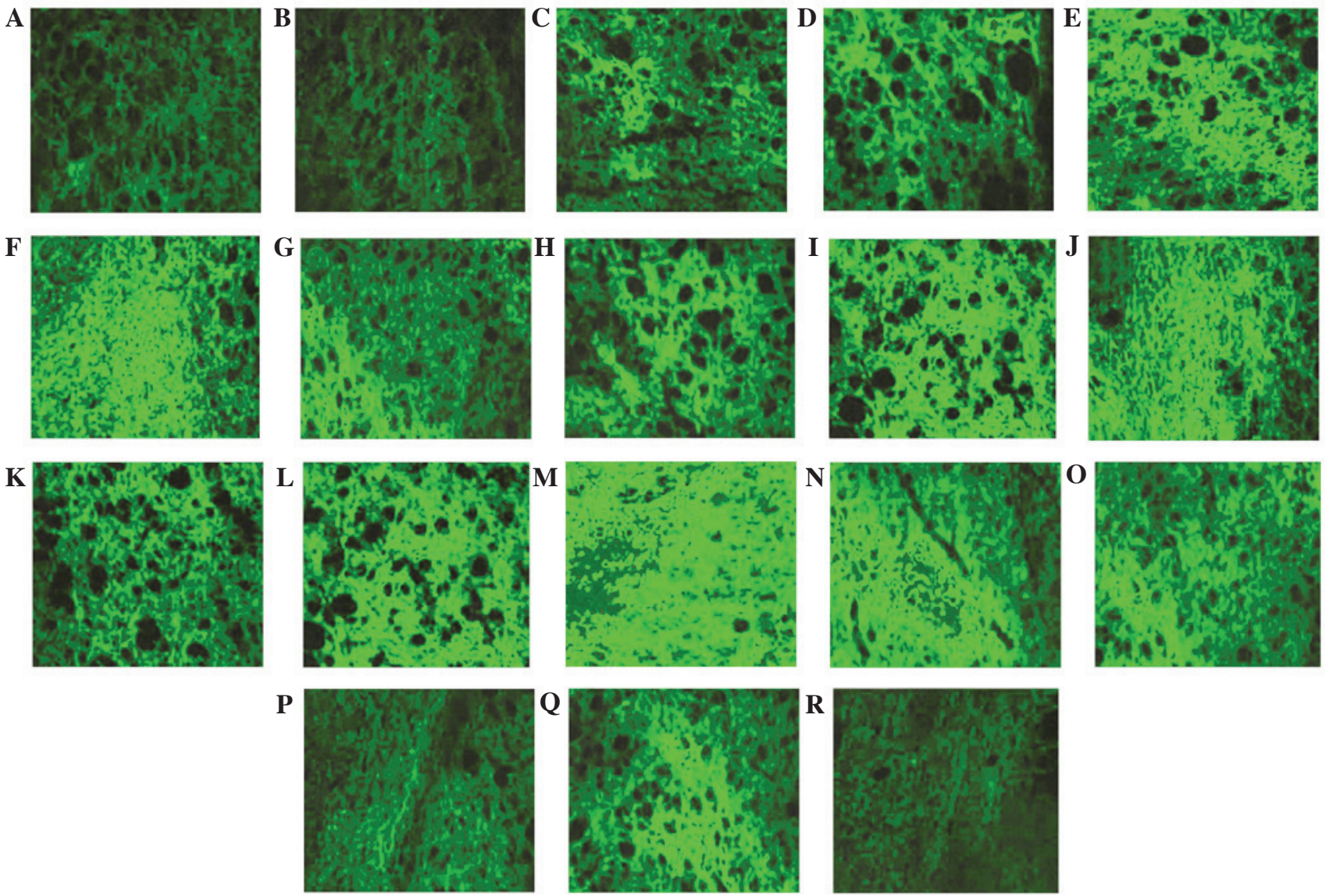

Figure 5. Cyanine3 immunofluorescent staining for $\mathrm{GABA}_{\mathrm{A}} \mathrm{R} \alpha 1 \sigma$ subunits of the hypothalamus of the REM sleep-deprived rats (magnification, $\mathrm{x} 20$ ). SD 5 day in the (A) CC and (B) TC groups. (C) SD 1 day, (D) SD 3 day, (E) SD 5 day and (F) RS $6 \mathrm{~h}$ in the nonOP group. (G) SD 1 day, (H) SD 3 day, (I) SD 5 day and (J) RS $6 \mathrm{~h}$ in the Sham group. (K) SD 1 day, (L) SD 3 day, (M) SD 5 day, (N) RS $6 \mathrm{~h}$ and (O) RS $12 \mathrm{~h}$ in the gabazine group. (P) SD 3 day, (Q) SD 5 day and (R) RS $6 \mathrm{~h}$ in the NO-711 group. GABA, $\gamma$-aminobutyric acid; REM, rapid eye movement; Hcrt, hypocretin; SD, sleep deprived; RS, sleep recovery; CC, blank control; TC, environmental control; nonOP, non-operative control; Sham, sham operation control.

groups. The total number of Fos-positive cells at SD 3 day and SD 5 day was significantly increased, as compared with the CC group and TC group. Single-factor multi-level variance analysis at the various time points in each group indicated that the increase in the number of $\mathrm{F}^{+} \& \mathrm{H}^{+}$cells was positively correlated with the duration of REM sleep deprivation. No significant differences were detected in the number of Fos-positive and $\mathrm{F}^{+} \& \mathrm{H}^{+}$cells at RS $6 \mathrm{~h}$ and $\mathrm{RS} 12 \mathrm{~h}$.

Tiagabine and gabazine have diametrically opposite effects on the number of Fos-positive and $\mathrm{F}^{+} \& \mathrm{H}^{+}$cells (33).
Therefore, this suggests that the GABA nerve system may also participate in the regulation of increased Hcrt nerve system activity arising from REM sleep deprivation.

In the present study, GABA content and $\mathrm{GABA}_{\mathrm{A}} \mathrm{R} \alpha 1$ expression in the hypothalamus significantly increased among normal rats following REM sleep deprivation in the nonOP group. The degree of this increase was positively correlated with the duration of REM sleep deprivation and, although it returned back to normal following sleep recovery, remained higher than the CC and TC groups. No differences between 
the $\mathrm{CC}$ and TC groups were detected at RS $12 \mathrm{~h}$. This increase in GABA content and $\mathrm{GABA}_{\mathrm{A}} \mathrm{R} \alpha 1$ expression indicated that the GABA nerve system strengthens. Therefore suggesting that REM sleep deprivation is capable of strengthening the role of the GABA nerve system in the hypothalamus.

In the present study, the degree of increase was positively correlated with the duration of REM sleep deprivation. However, it was demonstrated that this alteration returns to normal at RS $12 \mathrm{~h}$. During REM sleep deprivation and recovery, the GABA nerve system has its own regulation mechanism, which is a protective physiological process (34). The role of the GABA nerve system is positively correlated with the damage to the $\mathrm{CF}$; therefore a stronger role of the GABA nerve system will induce more severe damage to $\mathrm{CF}$ (35). Furthermore, the activity of the Hcrt nerve system is positively correlated with the GABA nerve system, as one regulates the other (36).

In conclusion, in terms of the decline of $\mathrm{CF}$ in rats induced by REM sleep deprivation, the GABA nerve system is not an ideal therapeutic target for the treatment of insomnia, whereas the Hcrt nerve system may hold greater potential as a therapeutic target.

\section{Acknowledgements}

The present study was funded by the following projects: The Nature Science Foundation of Inner Mongolia Autonomous Region (grant no. 2013MS1224); the National Natural Science Foundation of China (grant nos. 81260571, 81560801 and 81550047); the Public Health Project of the State Administration of Traditional Chinese Medicine (grant no. gjzyyglj11aglnzd); the Inner Mongolia Autonomous Region Mongolian Medicine Cooperative Innovation Project; and the Inner Mongolia Autonomous Region "Prairie excellence" Project.

\section{References}

1. Kanda T, Tsujino N, Kuramoto E, Koyama Y, Susaki EA, Chikahisa S and Funato H: Sleep as a biological problem: An overview of frontiers in sleep research. J Physiol Sci 66: 1-13, 2016.

2. Khadra MA, McConnell K, VanDyke R, Somers V, Fenchel M, Quadri S, Jefferies J, Cohen AP, Rutter M and Amin R: Determinants of regional cerebral oxygenation in children with sleep-disordered breathing. Am J Respir Crit Care Med 178: 870-875, 2008.

3. McDevitt EA, Rowe KM, Brady M, Duggan KA and Mednick SC: The benefit of offline sleep and wake for novel object recognition. Exp Brain Res 232: 1487-1496, 2014.

4. Spoormaker VI, Gvozdanovic GA, Sämann PG and Czisch M: Ventromedial prefrontal cortex activity and rapid eye movement sleep are associated with subsequent fear expression in human subjects. Exp Brain Res 232: 1547-1554, 2014.

5. Schmitt K, Holsboer-Trachsler E and Eckert A: BDNF in sleep, insomnia, and sleep deprivation. Ann Med 48: 42-51, 2016.

6. McCarley RW: Neurobiology of REM and NREM sleep. Sleep Med 8: 302-330, 2007.

7. Reilly T and Piercy M: The effect of partial sleep deprivation on weight-lifting performance. Ergonomics 37: 107-115, 1994.

8. Vazquez-DeRose J, Schwartz MD, Nguyen AT, Warrier DR, Gulati S, Mathew TK, Neylan TC and Kilduff TS: Hypocretin/orexin antagonism enhances sleep-related adenosine and GABA neurotransmission in rat basal forebrain. Brain Struct Funct 221: 923-940, 2016.

9. Sack RL, Auckley D, Auger RR, Carskadon MA, Wright KP, Vitiello MV and Zhdanova IV: Circadian rhythm sleep disorders: Part I, basic principles, shift work and jet lag disorders. An American Academy of Sleep Medicine review. Sleep 30: 1460-1483, 2007
10. Mileykovskiy BY, Kiyashchenko LI and Siegel JM: Behavioral correlates of activity in identified Hypocretin/orexin neurons. Neuron 46: 787-798, 2005.

11. Sakurai T, Nagata R, Yamanaka A, Kawamura H, Tsujino N, Muraki Y, Kageyama H, Kunita S, Takahashi S, Goto K, et al: Input of orexin/Hypoeretin neurons revealed by a genetically encoded tracer in mice. Neuron 46: 297-308, 2005.

12. Yoshida K, McCormack S, España RA, Crocker A and Scammell TE: Afferents to the orexin neurons of the rat brain. J Comp Neurol 494: 845-861, 2006.

13. Black SW, Morairty SR, Fisher SP, Chen TM, Warrier DR and Kilduff TS: Almorexant promotes sleep and exacerbates cataplexy in a murine model of narcolepsy. Sleep 36: 325-336, 2013.

14. Yang L, Zou B, Xiong X, Pascual C, Xie J, Malik A, Xie J, Sakurai T and Xie XS: Hypocretin/orexin neurons contribute to hippocampus-dependent social memory and synaptic plasticity in mice. J Neurosci 33: 5275-5284, 2013.

15. Kwon Jeong J, Dae Kim J and Diano S: Ghrelin regulates hypothalamic prolyl carboxypeptidase expression in mice. Mol Metab 2: 23-30, 2013.

16. Pan G, Li Y, Geng HY, Yang JM, Li KX and Li XM: Preserving GABAergic interneurons in acute brain slices of mice using the N-methyl-D-glucamine-based artificial cerebrospinal fluid method. Neurosci Bull 31: 265-270, 2015.

17. Figini M, Zucca I, Aquino D, Pennacchio P, Nava S, Di Marzio A, Preti MG, Baselli G, Spreafico R and Frassoni C: In vivo DTI tractography of the rat brain: An atlas of the main tracts in Paxinos space with histological comparison. Magn Reson Imaging 33: 296-303, 2015.

18. Cohen HB and Dement WC: Sleep: Changes in threshold to electrocon-vulsive shock in rats after deprivation of 'paradoxical' phase. Science 150: 1318-1319, 1965.

19. Jiang J, Liu F, Fang W and Liu Y: Effect of artificial cerebrospinal fluid lavage time on the edema of traumatic brain injury. Zhong Nan Da Xue Xue Bao Yi Xue Ban 38: 510-516, 2013 (In Chinese).

20. Ting CH, Huang HN, Huang TC, Wu CJ and Chen JY: The mechanisms by which pardaxin, a natural cationic antimicrobial peptide, targets the endoplasmic reticulum and induces c-FOS. Biomaterials 35: 3627-3640, 2014

21. Shehab S, D'souza C, Ljubisavljevic M and Redgrave P: High-frequency electrical stimulation of the subthalamic nucleus excites target structures in a model using c-fos immunohistochemistry. Neuroscience 270: 212-225, 2014.

22. Deng Y, Wang W, Yu P, Xi Z, Xu L, Li X and He N: Comparison of taurine, GABA, Glu, and Asp as scavengers of malondialdehyde in vitro and in vivo. Nanoscale Res Lett 8: 190, 2013.

23. Fievisohn EM, Sajja VS, Vandevord PJ and Hardy WN: Evaluation of impact-induced traumatic brain injury in the Göttingen minipig using two input modes. Traffic Inj Prev 15 (Suppl 1): S81-S87, 2014.

24. Ganji SK, An Z, Banerjee A, Madan A, Hulsey KM and Choi C: Measurement of regional variation of GABA in the human brain by optimized point-resolved spectroscopy at $7 \mathrm{~T}$ in vivo. NMR Biomed 27: 1167-1175, 2014.

25. Liu C, Liu X and Liu S: Bifurcation analysis of a Morris-Lecar neuron model. Biol Cybern 108: 75-84, 2014.

26. Perentos N, Martins AQ, Watson TC, Bartsch U, Mitchell NL, Palmer DN, Jones MW and Morton AJ: Translational neurophysiology in sheep: Measuring sleep and neurological dysfunction in CLN5 Batten disease affected sheep. Brain 138: 862-874, 2015.

27. Corsi-Cabrera M, Sifuentes-Ortega R, Rosales-Lagarde A, Rojas-Ramos OA and Del Río-Portilla Y: Enhanced synchronization of gamma activity between frontal lobes during REM sleep as a function of REM sleep deprivation in man. Exp Brain Res 232: 1497-1508, 2014.

28. Sansa G, Falup-Pecurariu C, Salamero M, Iranzo A and Santamaria J: Non-random temporal distribution of sleep onset REM periods in the MSLT in narcolepsy. J Neurol Sci 341: 136-138, 2014.

29. Descamps A, Rousset C, Dugua H, Debilly G, Delagrange P and Cespuglio R: Agomelatine restores a physiological response to stress in the aged rat. Neurosci Lett 566: 257-262, 2014.

30. Kutbay Özçelik H, Akkoyunlu ME, Bostanlı P, Bayram M, Atahan E, Sezer M, Karaköse F and Kart L: The frequency and properties of REM related obstructive sleep apnea among the patients with mild related obstructive sleep apnea. Tuberk Toraks 61: 283-287, 2013 (In Turkish). 
31. Oruna-Concha MJ, Methven L, Blumenthal H, Young $\mathrm{C}$ and Mottram DS: Differences in glutamic acid and 5'-ribonucleotide contents between flesh and pulp of tomatoes and the relationship with umami taste. J Agric Food Chem 55: 5776-5780, 2007.

32. Lee S, Yoon BE, Berglund K, Oh SJ, Park H, Shin HS, Augustine GJ and Lee CJ: Channel-mediated tonic GABA release from glia. Science 330: 790-796, 2010.

33. Llado-Pelfort L, Santana N, Ghisi V, Artigas F and Celada P. 5-HT1A receptor agonists enhance pyramidal cell firing in prefrontal cortex through a preferential action on GABA interneurons. Cereb Cortex 22: 1487-1497, 2012.
34. Iyer SR: Sleep and type 2 diabetes mellitus- clinical implications. J Assoc Physicians India 60: 42-47, 2012.

35. Wei H, Koivisto A, Saarnilehto M, Chapman H, Kuokkanen K, Hao B, Huang JL, Wang YX and Pertovaara A: Spinal transient receptor potential ankyrin 1 channel contributes to central pain hypersensitivity in various pathophysiological conditions in the rat. Pain 152: 582-591, 2011.

36. Ciriello J, Caverson MM and Li Z: Effects of hypocretin and norepinephrine interaction in bed nucleus of the stria terminalis on arterial pressure. Neuroscience 255: 278-291, 2013. 